\section{Polymerase chain reaction versus culture in the diagnosis of Helicobacter pylori infection}

\author{
Rune Johannessen, ${ }^{1}$ Kåre Bergh,,3 \\ Constantin Jianu, ${ }^{4}$ \\ Per Martin Kleveland ${ }^{1,4}$ \\ 1 Unit for Gastroenterology, Department \\ of Cancer Research and Molecular \\ Medicine, Norwegian University \\ of Science and Technology, Trondheim; \\ 2Department of Laboratory Medicine, \\ Children's and Women's Health, \\ Norwegian University of Science and \\ Technology, Trondheim; ${ }^{3}$ Department \\ of Medical Microbiology, \\ Clinic of Laboratory Medicine,
}

St. Olavs Hospital, Trondheim University

Hospital, Trondheim; ${ }^{4}$ Department

of Gastroenterology, Clinic of Medicine,

St. Olavs Hospital, Trondheim University

Hospital, Trondheim, Norway

\section{Abstract}

In the management of Helicobacter pyloriinduced gastroduodenal disease, a pilot study at our hospital (St. Olavs Hospital, Trondheim University Hospital, Trondheim, Norway) revealed that culture often seemed to fail compared to the polymerase chain reaction (PCR). A more thorough evaluation was therefore undertaken. We included 201 patients referred to upper gastrointestinal endoscopy in the period 2002-2004. Serology, biopsy rapid urease test, culture and PCR were performed. Conventional PCR was performed using the ure $C$, vacA and cagA genes, and real-time PCR for $u r e C$. A diagnostic standard was defined on the basis of all four tests, and all four tests were then compared to this standard. One hundred eleven patients were deemed $H$. pylori-positive by the defined diagnostic standard, and 90 were labeled negative. Compared to this standard, culture showed a sensitivity of $87.4 \%$, which was significantly lower than PCR at $99.1 \%(\mathrm{P}<0.001)$. Culture showed a perfect specificity of $100 \%$, which was significantly better than PCR at $97.8 \%$. ureC was the gene with the best sensitivity (94.6\% in conventional PCR, 97.3\% in real-time PCR). vacA sensitivity was $87.4 \%$, which is significantly lower than ureC $(\mathrm{P}<0.001)$. cagA was present in $37.8 \%$ of our $H$. pylori-positive patients. By real-time PCR a significantly lower cycle threshold was observed in antral biopsies than in corpal biopsies, indicating a higher $\mathrm{H}$. pylori DNA template concentration in antral biopsies. PCR-testing for $H$. pylori is faster and significantly more sensitive than culture. Culture on the other hand was significantly more specific than PCR in our hand.

\section{Introduction}

Diagnostic methods for the detection of Helicobacter pylori (H. pylori) are traditionally divided into invasive and non-invasive techniques based upon the need for endoscopy. The choice of test depends mostly on clinical situation, availability, population prevalence of infection and factors such as the use of antibiotics and proton pump inhibitors which may influence test results. Advantages of non-invasive tests are mainly their non-invasiveness and their independency of bacterial colonization density and distribution variability of the pathogen in the gastric mucosa. ${ }^{1} \mathrm{H}$. pylori can be detected noninvasively by serology, ${ }^{2}$ stool antigen tests and by urea breath testing. ${ }^{3,4}$

Gastroscopy, nevertheless, is often indicated in the management of $H$. pylori induced gastroduodenal disease. Biopsy histology provides essential information on the status of the mucosa and biopsy-based culture detects $H$. pylori with high specificity and under optimal conditions with excellent sensitivity. ${ }^{5}$ Besides diagnosing active infection, culture also offers the possibility of performing resistance testing for a variety of antimicrobial agents. ${ }^{1}$ Nevertheless, the sensitivity of biopsy-based tests and culture is significantly influenced by the density, viability and distribution of bacteria in the gastric mucosa. ${ }^{6}$ In certain circumstances, e.g. short time after use of antibiotics, recent or ongoing use of proton pump inhibitors (PPI), and in patients with gastric mucosal atrophy, biopsy based methods may fail due to biopsy sampling error. ${ }^{1}$ Culture can also fail due to incorrect transportation, processing and culturing conditions. ${ }^{1}$ Genetic methods can also be used to detect $H$. pylori in gastric biopsies and are recently shown to increase sensitivity of $H$. pylori detection compared to culture. .,8 $^{7}$

Besides accurately detecting $H$. pylori encompassing also non-culturable coccoid forms, ${ }^{9}$ polymerase chain reaction (PCR) can be employed for strain characterization by detecting genes encoding pathogenic factors and identifying certain resistance traits by detecting microbial gene mutations. ${ }^{10}$ PCR entails no special requirements in processing and transport, enabling a rapid and probably a cost-effective diagnosing of $H$. pylori, overcoming the delay associated with conventional culture methods. ${ }^{10-12}$

About ten years ago, after having used a conventional PCR method as a supplement to our standard $H$. pylori culture in gastric
Correspondence: Rune Johannessen, Clinic of Medicine, St. Olavs Hospital, N-7006 Trondheim, Norway. Tel. +47.93009665 .

E-mail: rune.trondheim@gmail.com

Key words: culture, helicobacter pylori, polymerase chain reaction.

Contributions: RJ, analysis of data, writing and revising manuscript; $\mathrm{KB}$, design of study, collection of data, analysis of data, writing and revising manuscript; CJ, design of study, collection of data, analysis of data, revising manuscript; PMK, design of study, collection of data, analysis of data, writing and revising manuscript.

Conflict of interests: the authors declare no potential conflict of interests.

Received for publication: 20 June 2012.

Revision received: 3 October 2012.

Accepted for publication: 3 December 2012.

This work is licensed under a Creative Commons Attribution NonCommercial 3.0 License (CC BYNC 3.0).

(C) Copyright R. Johannessen et al., 2013

Licensee PAGEPress, Italy

Gastroenterology Insights 2013; 5:e1

doi:10.4081/gi.2013.e1

mucosal biopsy specimens, a preliminary investigation in our hospital disclosed that culture often seemed to fail compared to PCR. Culture gave a negative result in as much as $27 \%$ of PCR-positive biopsies, whereas $5 \%$ of positive cultures were found to have a negative PCR-result, necessitating a more thorough evaluation of the biopsy-based diagnostic methods in use. We aimed primarily to compare culture and PCR. Biopsy rapid urease test (RUT) and serology were added to the protocol in order to evaluate conflicting results between culture and PCR. Secondarily, we wanted to investigate how the three gene sequences selected (ure $C$, vacA, cagA $A$ ) were suited for detecting and characterizing $H$. pylori colonization. Finally, we aimed to assess whether real-time PCR was more accurate than conventional PCR.

\section{Materials and Methods}

\section{Patients}

Two hundred one patients consecutively recruited from patients referred for upper gastrointestinal endoscopy (UGE) in the period 2002-2004 were included. Evidence of $H$. pylori infection was sought by PCR, culture and a rapid urease test (RUT) of gastric biopsies and serology. 


\section{Upper gastrointestinal endoscopy}

UGE was done using GIF 140 gastroscopes (Olympus, Japan) and topical (spray) lidocaine anesthesia only, after an overnight fast. In total six biopsies were taken from the mucosa of the greater curvature; three from both antrum and corpus; one for rapid urease testing and two for culture and PCR. Singleuse biopsy forceps were used, and the endoscopes were manually and mechanically cleaned using glutaraldehyde as disinfectant, followed by a machine wash using Olympus Europe equipment.

\section{H. pylori serology}

Whole blood samples were drawn and sera separated and stored at $-20^{\circ} \mathrm{C}$ until analyzed. IgG antibodies to $H$. pylori were determined by ELISA (Enzyme-Linked ImmunoSorbent Assay) using the commercial Pyloriset ${ }^{\circledR}$ EIA-G (Orion Diagnostics, Espoo, Finland). ${ }^{2}$

\section{Rapid urease test}

Urease testing was performed using the Hut-Test ${ }^{\circledR}$ (AstraZeneca, Sweden). ${ }^{13}$ The dual biopsy-specimen urease tests were observed in an incubator at $37^{\circ} \mathrm{C}$ and read at 1 hour; and if not positive read again at latest after an additional 24 hours according to the manufacturer's recommendations. ${ }^{13}$

\section{Microbiological methods}

\section{Culture}

Biopsy specimens were placed and transported in Stuart's medium to the microbiology department and processed the same day. Biopsies for culture were ground in $250-300 \mu \mathrm{L}$ of saline using a mortar and pestle. For culture $100 \mu \mathrm{L}$ was seeded onto a selective agar and incubated in a microaerophil environment as described previously. ${ }^{5}$ The agar plates were incubated for a period of ten days.

\section{Polymerase chain reaction}

After grinding the biopsy as described above, the suspension was subjected to heat lysis in an Eppendorf tube on a heating block for $15 \mathrm{~min}$ at
$95{ }^{\circ} \mathrm{C} .2 \mu \mathrm{L}$ of the lysate was used as template for PCR. Conventional PCR targeting the ureC, vacA and cagA genes was performed using PCR conditions as described elsewhere. ${ }^{10,14,15}$ Realtime PCR for ureC was performed using the same primers as for conventional PCR and by constructing a TaqMan probe. Details of DNA primer and probe sequences are given in Table 1. PCR was run on a LightCycler ${ }^{\circledR}$ (Roche Molecular Diagnostics, Switzerland) platform using the Light-Cycler-Fast Start DNA Master Hybridazation Probe kit. Final concentrations of primers, probe and $\mathrm{MgCl}_{2}$ were $0.5 \mu \mathrm{M}, 0.2 \mu \mathrm{M}$, and $4 \mathrm{mM}$, respectively. PCR conditions were: $95^{\circ} \mathrm{C}$ for $5 \mathrm{~min}$ to activate the Taq polymerase, and 45 cycles of $5 \mathrm{sec}$ at $95^{\circ} \mathrm{C}, 10 \mathrm{sec}$ at $55^{\circ} \mathrm{C}$ and $20 \mathrm{sec}$ at $72^{\circ} \mathrm{C}$. To control for inhibition of PCR in biopsy specimens a real-time PCR targeting human DNA was employed as described elsewhere. ${ }^{16}$

\section{Diagnostic standard definition}

Even though many tests for diagnosing $H$. pylori exist, no single test can be considered a gold standard. In the current study, a diagnostic standard was defined on the basis of the combined results from culture, PCR, RUT and serology. ${ }^{17}$

A test was defined as $H$. pylori positive if at least one of the following conditions were present: i) all 4 tests positive; ii) 3 tests positive, 1 test negative or missing/not performed; iii) PCR and culture positive, RUT and/or serology negative or missing/not performed.

Conversely, a test was considered negative if at least one of the following conditions were present: i) all 4 tests negative; ii) 3 tests negative, 1 test positive or missing/not performed; iii) PCR and culture negative, RUT and/or serology positive or missing/not performed.

Four cases did not meet any of the above listed criteria for $H$. pylori status. These patients are described in detail under results, and labeled as negative or positive on the basis of all available information. Culture, PCR, RUT and serology were then compared to this defined diagnostic standard (Table 2).

\section{Statistical analysis}

Test accuracies are proportions, and were therefore compared using the $\chi^{2}$-test. The level of significance was set to $\mathrm{P}<0.05$. Mean Ct-values in antral and corpal biopsies were compared with a paired Student's t-test. All analyses were performed using SPSS (Statistical Package for the Social Sciences) versions 14.0-18.0.2.

\section{Ethics}

This study was approved by the regional ethics committee of the Norwegian University of Science and Technology in Trondheim, Norway. Informed consent was obtained from all participants.

\section{Results}

Our material comprised 201 patients with a mean age of 60 years (range 15-92), 93 of who were women (46\%). Results from PCR and culture were registered for all 201 patients. Valid results from serology and rapid urease test were recorded in 188 (94\%) and 183 (91\%) patients, respectively (Table 3 ). In the remaining cases these two analyses were either not performed, or the results could not be retrieved. All patients had valid results for at least three tests.

In total, 111 patients were labeled as $H$. pylori positive by our defined diagnostic standard. Seventy-four of these were positive by all 4 tests, while 35 had 3 positive tests. Two patients did not meet the defined criteria for $H$. pylori positivity, but were labeled as positive after review of all available information. The first patient, a 76 years old man, had not gone through any prior anti-H. pylori (anti-HP) treatment, and was referred to endoscopy because of heartburn, acid regurgitation, epigastric pain and anemia with melena. He had a comorbidity of chronic obstructive pulmonary disease. Endoscopy showed esophagitis grade C (Los Angeles classification) and a fibrin-covered duodenal ulcer. RUT was negative, but serology positive with a titer of 88 .

Table 1. Details of DNA sequences employed as primers and TaqMan probe for the detection of Helicobacter pylori in biopsy specimens.

\begin{tabular}{|c|c|c|c|}
\hline Target gene & Primer and probe sequence $\left(5^{\prime}-3^{\prime}\right)$ & Product size (bp) & Reference \\
\hline ureC $^{*}$ & $\begin{array}{c}\text { AAGCTTTTAGGGGTGTTAGGGGTTT } \\
\text { AAGCTTACTTTCTAACACTAACGC } \\
\text { 6-FAM-CGATTGGGGATAAGTTTGTGAGCG-TAMRA }\end{array}$ & 294 & $\begin{array}{l}14 \\
\text { This study }\end{array}$ \\
\hline vacA & $\begin{array}{c}\text { GAGCGAGCTATGGTTATGAC } \\
\text { ACTCCAGCATTCATATAGA }\end{array}$ & 229 & 10 \\
\hline $\operatorname{cag} A$ & $\begin{array}{l}\text { AATACACCAACGCCTCCAAG } \\
\text { TTGTTGCCGCTTTTGCTCTC }\end{array}$ & 400 & 15 \\
\hline
\end{tabular}

\footnotetext{
*ureC is now termed gene for phosphoglucosamine mutase; bp, base pairs.
} 
Culture was negative for antral and corpal biopsies. PCR was positive in both biopsies for the ure $C$ gene, but negative in both biopsies for vacA and cagA. The second patient, also male, was aged 22 years and presented with a 2-year long history of epigastric pain and heartburn. He had not been using any medication. Endoscopy showed esophagitis grade B (Los Angeles classification) and antral gastritis. Culture was negative in both biopsies, while RUT was positive after 1 hour. Serology was not performed. PCR was positive for all three genes in antral and corpal biopsies.

In total, 90 patients were labeled as $H$. pylori negative by our defined diagnostic standard. Twenty-five of these were negative by all 4 tests, while 47 had 3 negative tests; 16 had negative PCR and culture, and positive or missing RUT and/or serology; 2 patients did not meet the defined criteria for $H$. pylori negativity, but were labeled as negative after a review of all available information. The first patient, a man aged 35 years, had gone through anti-HP treatment because of peptic ulcer three years earlier, and now presented with dyspepsia. He had been using H2RA recently, in addition to penicillin tablets towards an airway infection during the last week before the endoscopy, which showed a slight injection of the bulbus duodeni. Serology was positive with a low titer of 27, and RUT was negative. Culture was negative for antral and corpal biopsies. Antral biopsies were weakly PCR-positive for ureC and vacA, and negative for $\operatorname{cag} A$. Corpal biopsies were PCRnegative for all three genes. The second patient, also male, was 60 years of age, without any known prior anti-HP therapy, presenting with heartburn. Endoscopy showed esophagitis grade B (Los Angeles classification) and antral gastritis. RUT was positive after 24 hours, while serology was negative. Culture was negative for antral and corpal biopsies. PCR was positive in antral biopsies for ureC and vacA, but negative for cagA. Corpal biopsies were negative for all three genes.

Compared to the defined diagnostic standard, PCR had a sensitivity of $99.1 \%$, culture $87.4 \%$, RUT $97.1 \%$ and serology $96.0 \%$ (Table 2). Culture was thus falsely negative in $12.6 \%$ of the patients, and PCR in $0.9 \%$. Culture had perfect specificity of $100 \%$, PCR $97.8 \%$. PCR was significantly more sensitive than culture, RUT and serology $(\mathrm{P}<0.001)$. ure $C$ was more sensitive than vacA and cagA $(\mathrm{P}<0.001)$. There was a tendency towards better sensitivity for real-time PCR compared with conventional PCR for ureC, but this difference did not reach statistical significance. No inhibition of PCR was evident in any of the biopsies investigated.

The prevalence of atrophic gastritis increases with age, and decreases bacterial density of H. pylori in the gastric mucosa. ${ }^{18}$ Recent antiHP or PPI treatment is also known to be associated with a lower bacterial density in the gastric mucosa. ${ }^{1}$ An ad-hoc subanalysis was done to compare results in subgroups of patients with presumably different bacterial densities (Tables

Table 2. Test accuracy when compared to a defined diagnostic standard.

\begin{tabular}{lcc} 
Variable & Sensitivity (\%) & Specificity (\%) \\
Serology & 96.0 & 63.2 \\
Rapid urease test & 97.1 & 55.7 \\
\hline Culture & 87.4 & 100 \\
PCR total & 99.1 & 97.8 \\
\hline Conventional PCR cagA & 37.8 & 100 \\
Conventional PCR vacA & 87.4 & 97.8 \\
\hline Conventional PCR ureC & 94.6 & 97.8 \\
Real-time PCR ureC & 97.3 & 97.8 \\
\hline
\end{tabular}

PCR, polymerase chain reaction. PCR total means result for all PCR analyses together. Diagnostic standard: see definition under methods.

Table 3. Results of different diagnostic methods.

\begin{tabular}{lccccc} 
Variable & N pos & $\%$ & N neg & $\%$ & N total \\
Serology & 129 & 69 & 59 & 31 & 188 \\
Rapid urease test & 136 & 74 & 47 & 26 & 183 \\
\hline Culture & 97 & 48 & 104 & 52 & 201 \\
PCR total & 112 & 56 & 89 & 44 & 201 \\
\hline Conventional PCR cagA & 42 & 21 & 159 & 79 & 201 \\
Conventional PCR vacA & 99 & 49 & 102 & 51 & 201 \\
\hline Conventional PCR ureC & 107 & 53 & 94 & 47 & 201 \\
Real-time PCR ureC & 110 & 55 & 91 & 45 & 201 \\
\hline
\end{tabular}

PCR, polymerase chain reaction. PCR total means result for all PCR analyses (positive test means that at least one gene was positive).

Table 4. Test accuracies in patients with presumably different bacterial densities, when compared to a defined diagnostic standard.

\begin{tabular}{|c|c|c|c|c|c|c|}
\hline \multirow[b]{2}{*}{ Test type } & \multirow{2}{*}{$\begin{array}{c}\text { High density ( } \mathrm{n}=153) \\
\text { Sens (\%) }\end{array}$} & \multicolumn{2}{|c|}{$\begin{array}{l}\text { Sensitivities } \\
\text { Low density }(n=48)\end{array}$} & \multirow{2}{*}{$\begin{array}{c}\text { High density }(\mathrm{n}=153) \\
\text { Spec }(\%)\end{array}$} & \multicolumn{2}{|c|}{$\begin{array}{l}\text { Specificities } \\
\text { Low density ( } n=48)\end{array}$} \\
\hline & & Sens (\%) & Sign & & Spec (\%) & Sign \\
\hline Serology & 95.5 & 100 & $<0.001$ & 70.9 & 50.0 & 0.002 \\
\hline Rapid urease test & 97.8 & 92.9 & ns & 60.0 & 48.3 & ns \\
\hline Culture & 89.7 & 71.4 & $<0.001$ & 100.0 & 100.0 & ns \\
\hline PCR total & 99.0 & 100.0 & $<0.001$ & 98.2 & 97.1 & ns \\
\hline Conventional PCR cagA & 39.2 & 28.6 & 0.021 & 100.0 & 100.0 & ns \\
\hline Conventional PCR vacA & 88.7 & 78.6 & 0.015 & 98.2 & 97.1 & ns \\
\hline Conventional PCR ureC & 95.9 & 85.7 & 0.004 & 98.2 & 97.1 & ns \\
\hline Real-time PCR ureC & 96.9 & 100 & $<0.001$ & 98.2 & 97.1 & ns \\
\hline
\end{tabular}

Sens, sensitivity; Spec, specificity; Sign, significance level of difference (P-value), based on $\chi^{2}$-test; ns, non-significant P-value (i.e. P>0.05); PCR, polymerase chain reaction.

Diagnostic standard: see definition under methods; High density: patients with a presumable high density of bacteria in the gastric mucosa, i.e. primary diagnostics (n=156); Low density: patients with a presumable low density of bacteria in the gastric mucosa, i.e. having received recent anti-HP or PPI therapy $(n=45)$. 
4 and 5). In patients that had received anti-HP or PPI treatment recently, culture showed a sensitivity of $71.4 \%$. The sensitivity in the opposite subgroup was $89.7 \%$, a difference which was highly significant $(\mathrm{P}<0.001) \quad($ Table 4). Comparing age groups, we found culture to be less sensitive in older patients ( $>75$ years), with a significant P-value of 0.016 (Table 5).

One hundred two patients had a positive realtime PCR biopsy in both the antrum and the corpus. 95 of these had retrievable data for quantification, i.e. the cycle threshold $(\mathrm{Ct})$ value. Lower $\mathrm{Ct}$ value indicates higher bacterial density in the biopsy. Mean Ct value for antrum biopsies was 30.65 (SD 3.60), and 31.52 in the corpus (SD 3.23). A paired t-test showed that this difference of 0.87 units is statistically significant with a P-value of 0.01 (Table 6). In subgroups of patients with presumably high bacterial densities, an even greater difference in the same direction was found, while there was no significant difference in subgroups with a presumably low bacterial density (Table 6).

\section{Discussion}

This study compared culture and PCR for detecting $H$. pylori, to a diagnostic standard which was based on the combined results of culture, PCR, serology and RUT. PCR was found to be significantly more sensitive than culture $(\mathrm{P}<0.001)$. Culture was found to be falsely negative in $12.6 \%$ of the cases, PCR only in $0.9 \%$. Culture was on the other hand found to have a perfect specificity, where as PCR was deemed falsely positive in $2.2 \%$ of the cases.

The results are in accordance with earlier studies comparing conventional PCR and culture and recent studies using improved PCRmethods, including quantitative real-time PCR, showing PCR to be far more sensitive than culture in detecting current $H$. pylori infection. ${ }^{1,8,19-22}$

Although culture from biopsy specimens has the potential of leading to a high sensitivity (>90\%) under optimal conditions, ${ }^{1,5,12}$ the literature reports sensitivity values of culture varying from $50 \%$ to $70 \%$ in experienced laboratories. ${ }^{1,22}$ Our sensitivity (87.4\%) seems to be comparable or better than the average of published values, ${ }^{1}$ but still renders $12.6 \%$ falsely negative results, only reflecting the fastidious character of the bacterium and the inevitable suboptimal accuracy of the method in detecting active $H$. pylori infection in this type of unselected patient material. Accordingly, in an ad hoc subanalysis, culture was found to be significantly less sensitive when used in older patients ( $>75 \mathrm{yrs}$ ) (Table 4), and in patients having had recent anti-HP therapy or PPI treatment (Table 5). This is in accordance with several other studies indicating that the infection in such patients has an uneven mucosal distribution of bacteria. ${ }^{1,18}$

Real-time PCR performed well regardless of age or recent anti-HP- or PPI-therapy (Tables 4 and 5). One patient was culture positive and PCR negative, while both serology and RUT were positive. This reflects a false negative PCR reaction, probably indicating that the number of bacteria was under the threshold of detection in the specimen investigated. The cultured strain did contain the $u r e C$ gene. In general, other reasons for a negative PCR would include polymorphism of the gene targeted or Taq polymerase inhibitors. ${ }^{23}$ Two patients in this study were deemed as false positive by PCR. False positive PCR reactivity, however seldom, is theoretically possible, probably by mechanism of the assay targeting exogenous DNA sharing genes with the PCR primers. ${ }^{11,23}$ That could occur in the presence of close relatives of $H$. pylori such as H.heilmannii in gastric mucosa, Campylobacter species originating from the oral cavity, gastric mucosal segments of $H$. pylori DNA from earlier treated infection, or contamination of material.

Quantitative results from real-time PCR in

Table 5. Test accuracies in different age groups, when compared to a defined diagnostic standard.

\begin{tabular}{|c|c|c|c|c|c|c|}
\hline Test type & \multicolumn{3}{|c|}{$\begin{array}{l}\text { Sensitivities } \\
>75 \text { yrs }(\mathrm{n}=43)\end{array}$} & $\begin{array}{c}\leq 75 \text { yrs }(n=158) \\
\text { Spec }(\%)\end{array}$ & \multicolumn{2}{|c|}{$\begin{array}{l}\text { Specificities } \\
\qquad 75 \text { yrs }(\mathrm{n}=43)\end{array}$} \\
\hline Serology & 96.1 & 95.8 & ns & 62.3 & 66.7 & ns \\
\hline Rapid urease test & 97.5 & 95.8 & ns & 58.7 & 43.8 & 0.017 \\
\hline Culture & 89.7 & 79.2 & 0.016 & 100 & 100 & ns \\
\hline PCR total & 98.9 & 100 & $<0.001$ & 97.2 & 100 & $<0.001$ \\
\hline Conventional PCR cagA & 39.1 & 33.3 & ns & 100 & 100 & ns \\
\hline Conventional PCR vacA & 90.8 & 75.0 & 0.001 & 97.2 & 100 & $<0.001$ \\
\hline Conventional PCR ureC & 95.4 & 91.7 & ns & 97.2 & 100 & $<0.001$ \\
\hline Real-time PCR & 96.6 & 100 & $<0.001$ & 97.2 & 100 & $<0.001$ \\
\hline
\end{tabular}

yrs, years of age; Sens, sensitivity; Spec, specificity; Sign, significance level of difference (P-value), based on $\chi^{2}$-test; ns, non-significant P-value (i.e. P $\left.>0.05\right)$; PCR, polymerase chain reaction. Diagnostic standard: see the definition under methods.

Table 6. Real-time polymerase chain reaction quantification values for different patient groups.

\begin{tabular}{lcccccc} 
Groups & $\mathrm{N}$ & $\mathrm{Ct}$ ant & $(95 \% \mathrm{CI})$ & Ct corpus & $(95 \% \mathrm{CI})$ & Sign \\
Positive real-time PCR & 95 & 30.65 & $(29.92-31.38)$ & 31.52 & $(30.86-32.18)$ & 0.01 \\
High density & 85 & 30.52 & $(29.72-31.31)$ & 31.66 & $(30.95-32.37)$ & 0.001 \\
\hline Low density & 10 & 31.77 & $(30.04-33.51)$ & 30.35 & $(28.68-32.03)$ & $\mathrm{ns}$ \\
Age $>75$ years & 22 & 30.70 & $(29.07-32.33)$ & 30.99 & $(30.01-31.98)$ & $\mathrm{ns}$ \\
\hline Age $\leq 75$ years & 73 & 30.63 & $(29.79-31.47)$ & 31.68 & $(30.87-32.49)$ & 0.006
\end{tabular}

Ct, Cycle threshold value for antral/corpal biopsies; CI, confidence interval; Sign, significance level of difference (P-value), based on a paired Student's t-test; ns, non-significant P-value (i.e. P>0.05); PCR, polymerase chain reaction. Positive real-time PCR: all patients with positive real-time PCR where Ct-value was recorded; High Density: patients with a presumably high density of bacteria in the gastric mucosa, i.e. primary diagnostics; Low Density: patients with a presumably low density of bacteria in the gastric mucosa, i.e. having received recent anti-HP or PPI therapy. 
our study showed a lower cycle threshold $(\mathrm{Ct})$ value in antral biopsies than in corpal biopsies (Table 6). The absolute difference was 0.87 units, which was statistically significant. Given an optimum PCR efficiency a Ct difference of 0.87 units would indicate that antral biopsies contain about $2^{0.87}=1.83$ times higher H. pylori DNA concentration than corpal biopsies, and will therefore have clinical relevance for $H$. pylori diagnosis. In other words, our study shows that real-time PCR is more sensitive in antrum biopsies. However, in subgroups of patients with a presumably low bacterial density, i.e. patients having received recent anti-HP or PPI therapy, no difference in Ctvalue was found between antrum and corpus (Table 6). This is in accordance with the established knowledge about the pathogenesis of $H$. pylori; The bacteria colonize the antrum of the stomach to avoid the acid-secreting parietal cells located in the corpus, and this mechanism is most prominent in patients with a high production of gastric acid. ${ }^{24}$ In patients with a presumably low bacterial density, i.e. patients having recently gone through anti-HP or PPI treatment, the colonization pattern can be somewhat different.

The $u r e C$ gene was not surprisingly found to be significantly more sensitive than vacA and cagA in detecting $H$. pylori through PCR. ureC codes for phosphoglucosamine mutase, an enzyme essential for the survival of $H$. pylori. ${ }^{7}$ It is present in all strains of the bacterium and has been shown to be well suited as a tracing gene. ${ }^{1,14}$ Both vacA and cagA code for proteins that act as virulence factors. The vacA gene, though also present in all strains, shows considerable polymorphism, ${ }^{25}$ which could explain it to be less sensitive than $u r e C$ as a molecular diagnostic marker for $H$. pylori. ${ }^{10,14}$ We found cagA to be present in $37 \%$ of the $H$. pylori strains in our study, which is in agreement with the low prevalences reported in Western populations. ${ }^{26,27}$

There was a tendency towards better sensitivity for real-time PCR than conventional PCR, but the difference did not reach statistical significance. Real-time PCR is faster and offers several important advantages over conventional PCR; quantification and possibility for detection of mutations associated with antibiotic resistance. ${ }^{1,20,28,29}$ Real-time PCR has therefore become the routine method for detecting H. pylori in our hospital.

The sensitivity and specificity of rapid urease testing in this study was $97.1 \%$ and $55.7 \%$, respectively (Table 2). We performed as recommended a delayed reading of the Hut-Test ${ }^{\circledR}$ agar after 24 hours when initial reading (1 hour) was negative. ${ }^{13}$ This increases sensitivity, but could also explain the low specificity in our patients, because delayed reading increases the possibility of interference from other urease positive bacteria in the gastric and oral mucosa. $1,30,31$

Sensitivity and specificity for serology was found to be $96.0 \%$ and $63.2 \%$, respectively (Table 1). Corresponding values has been published recently in a similar populations. ${ }^{18}$ The low specificity of serology probably reflects acid suppression or recent clearance of infection in a substantial proportion of patients (Table 4). ${ }^{32}$

A possible question that can be raised about the current study is the solidity of the defined diagnostic standard. To sum up, all 4 tests were in agreement in 99 of 201 patients. Three tests were in agreement in a further 63 patients: 39 patients had two tests in agreement, whereof 35 showed agreement between culture and PCR; 4 patients had to be reviewed in detail to establish their most probable $H$. pylori status. The utmost care was taken to ensure a correct labeling of $H$. pylori status, but the possibility of erratic labeling must still be acknowledged.

\section{Conclusions}

In summary, a universal gold standard assay for the diagnosis of $H$. pylori has not yet been established. The diagnosis of $H$. pylori should be carried out in light of the clinical setting, and often a combination of assays is necessary. When patients have an upper endoscopy with biopsy harvesting, PCR, especially realtime PCR, offers several advantages over culture. It is arguably less labor-intensive, less vulnerable, faster, and more sensitive. In our hand the best sensitivity was achieved using the ure $C$ gene. Our routine for detection of $H$. pylori is now PCR, supplemented by culture only in patients with failed empiric eradication therapy and demand for testing of antibiotic resistance for identification and evaluation of effective $H$. pylori therapies.

\section{References}

1. Megraud F, Lehours P. Helicobacter pylori detection and antimicrobial susceptibility testing. Clin Microbiol Rev 2007;20:280322.

2. Feldman RA, Deeks JJ, Evans SJ. Multi-laboratory comparison of eight commercially available Helicobacter pylori serology kits. Helicobacter pylori Serology Study Group. Eur J Clin Microbiol Infect Dis 1995;14: 428-33.

3. Makristathis A, Barousch W, Pasching E, et al. Two enzyme immunoassays and PCR for detection of Helicobacter pylori in stool specimens from pediatric patients before and after eradication therapy. J Clin Microbiol 2000;38:3710-4.
4. Graham DY, Klein PD, Evans DJ Jr., et al. Campylobacter pylori detected noninvasively by the $13 \mathrm{C}$-urea breath test. Lancet 1987;1:1174-7.

5. Maeland JA, Kleveland PM, Naess AI. Contribution of antibodies reacting with Campylobacter jejuni antigens in the testing of human sera for anti-Helicobacter pylori antibodies. Serodiagn Immunother Infect Dis 1993;1:32-6.

6. Bayerdorffer E, Oertel H, Lehn N, et al. Topographic association between active gastritis and Campylobacter pylori colonisation. J Clin Pathol 1989;42:834-9.

7. De Reuse H, Labigne A, Mengin-Lecreulx D. The Helicobacter pylori ureC gene codes for a phosphoglucosamine mutase. J Bacteriol. 1997;179:3488-93.

8. He Q, Wang JP, Osato M, Lachman LB. Real-time quantitative PCR for detection of Helicobacter pylori. J Clin Microbiol $2002 ; 40: 3720-8$.

9. Shahamat M, Alavi M, Watts JE, et al. Development of two PCR-based techniques for detecting helical and coccoid forms of Helicobacter pylori. J Clin Microbiol 2004;42:3613-9.

10. Chisholm SA, Owen RJ, Teare EL, Saverymuttu S. PCR-based diagnosis of Helicobacter pylori infection and real-time determination of clarithromycin resistance directly from human gastric biopsy samples. J Clin Microbiol 2001;39:1217-20.

11. Hardin FJ, Wright RA. Helicobacter pylori: review and update. Hosp Physician 2002: 23-31.

12. Hirschl AMAM, Makristathis AA. Methods to detect Helicobacter pylori: from culture to molecular biology. Helicobacter 2007;12 Suppl 2:6-11.

13. Heckenmuller $H$, Irvens A. HUT test ${ }^{\circledR}$. A new rapid urease test - pharmaceutical aspects. Deutsch Apothek 1995;47:1-7.

14. Bickley J, Owen RJ, Fraser AG, Pounder RE. Evaluation of the polymerase chain reaction for detecting the urease $\mathrm{C}$ gene of Helicobacter pylori in gastric biopsy samples and dental plaque. J Med Microbiol 1993;39:338-44.

15. Kabir S. Detection of Helicobacter pylori in faeces by culture, PCR and enzyme immunoassay. J Med Microbiol 2001;50: 1021-9.

16. Bergseng H, Bevanger L, Rygg M, Bergh K. Real-time PCR targeting the sip gene for detection of group B Streptococcus colonization in pregnant women at delivery. $\mathrm{J}$ Med Microbiol 2007;56:223-8.

17. Andersen LP, Kiilerick S, Pedersen G, et al. An analysis of seven different methods to diagnose Helicobacter pylori infections. Scand J Gastroenterol 1998;33:24-30.

18. Shin CM, Kim N, Lee HS, et al. Validation of diagnostic tests for Helicobacter pylori 
with regard to grade of atrophic gastritis and/or intestinal metaplasia. Helicobacter 2009;14:512-9.

19. Hammar M, Tyszkiewicz T, Wadstrom T, 0'Toole PW. Rapid detection of Helicobacter pylori in gastric biopsy material by polymerase chain reaction. J Clin Microbiol 1992;30:54-8.

20. Pacheco N, Mago V, Gomez I, et al. Comparison of PCR and common clinical tests for the diagnosis of $\mathrm{H}$. pylori in dyspeptic patients. Diagn Microbiol Infect Dis 2001;39:207-10.

21. Lage AP, Godfroid E, Fauconnier A, et al. Diagnosis of Helicobacter pylori infection by PCR: comparison with other invasive techniques and detection of cagA gene in gastric biopsy specimens. J Clin Microbiol 1995;33:2752-6.

22. Ndip RN, MacKay WG, Farthing MJ, Weaver LT. Culturing Helicobacter pylori from clinical specimens: review of microbiologic methods. J Pediatr Gastroenterol Nutr 2003;36:616-22.
23. Monteiro L, Birac C, Megraud F. Detection of Helicobacter pylori in gastric biopsy by polymerase chain reaction. In: Lee A, Megraud F, eds. Helicobacter Pylori: techniques for clinical diagnosis and basic research. London: WB Saunders Co Ltd; 1996. pp 112-119.

24. Kusters JG, van Vliet AH, Kuipers EJ. Pathogenesis of Helicobacter pylori infection. Clin Microbiol Rev 2006;19:449-90.

25. Chung C, Olivares A, Torres E, et al. Diversity of VacA intermediate region among Helicobacter pylori strains from several regions of the world. J Clin Microbiol 2010;48:690-6.

26. Peek RM, Jr., Crabtree JE. Helicobacter infection and gastric neoplasia. J Pathol 2006;208:233-48.

27. Husson M0, Gottrand F, Vachee A, et al. Importance in diagnosis of gastritis of detection by PCR of the cagA gene in Helicobacter pylori strains isolated from children. J Clin Microbiol 1995;33:3300-3.

28. Chisholm SA, Owen RJ. Application of polymerase chain reaction-based assays for rapid identification and antibiotic resistance screening of Helicobacter pylori in gastric biopsies. Diagn Microbiol Infect Dis 2008;61:67-71.

29. Monteiro L, Oleastro M, Lehours P, Megraud F. Diagnosis of Helicobacter pylori infection. Helicobacter 2009;14 Suppl 1:8-14.

30. Schrader JA, Peck HV, Notis WM, et al. A role for culture in diagnosis of Helicobacter pylori-related gastric disease. Am J Gastroenterol 1993;88:1729-33.

31. Prince MI, Osborne JS, Ingoe L, et al. The CLO test in the UK: inappropriate reading and missed results. Eur J Gastroenterol Hepatol 1999;11:1251-4.

32. Luthra GK, DiNuzzo AR, Gourley WK, Crowe SE. Comparison of biopsy and serological methods of diagnosis of Helicobacter pylori infection and the potential role of antibiotics. Am J Gastroenterol 1998;93:1291-6. 